\title{
Weight Gain and Alcohol Drinking Associations with Breast Cancer Risk in Japanese Postmenopausal Women - Results from the Japan Collaborative Cohort (JACC) Study
}

\author{
Junichi Nitta ${ }^{1}$, Masanori Nojima ${ }^{2}$, Hirofumi Ohnishi ${ }^{1}$, Mitsuru Mori ${ }^{1 *}$, Kenji \\ Wakai $^{3}$, Sadao Suzuki ${ }^{4}$, Yoshihisa Fujino ${ }^{5}$, Yingsong Lin $^{6}$, Koji Tamakoshi ${ }^{7}$, \\ Akiko Tamakoshi ${ }^{8}$
}

\begin{abstract}
Background: We investigated four factors, height, weight gain since age 20 , physical activity, and alcohol drinking, for associations with risk of breast cancer (BC) according to menopausal status, using the latest data of the Japan Collaborative Cohort Study (JACC Study). Materials and Methods: We confined the analysis to 24 areas available of cancer incidence information, excluding women with a previous diagnosis of $\mathrm{BC}$. Baseline data were collected from 38,610 (9,367 premenopausal, and 29,243 postmenopausal) women during 1988 and 1990. The study subjects were followed-up at the end of 2009, and 273 ( 84 premenopausal, and 189 postmenopausal) cases of $\mathrm{BC}$ were newly diagnosed in 501,907 person-years. The Cox model was used to estimate a hazards ratio (HR) and its 95\% confidence interval (CI) of BC risk. Results: As a result of the multivariate analysis adjusting for age at baseline survey, age at menarche, number of live births, and, age at first delivery, weight gain since age 20 of $6.7 \mathrm{~kg}-9.9 \mathrm{~kg}$, and $\geq 10.0 \mathrm{~kg}$ were significantly associated with increased risk for postmenopausal BC (HR=2.48, 95\% CI 1.40-4.41, and, HR=2.94, 95\% CI 1.84-4.70, respectively). Significantly increased trend of BC risk was also observed in weight gain since age 20 ( $p$ for trend, $p<0.001$ ). Amount of ethanol intake per day $\geq 15.0$ $\mathrm{g}$ was significantly associated with increased risk for postmenopausal $\mathrm{BC}$ in the multivariable-adjusted analysis (HR=2.74, 95\% CI 1.32-5.70). Conclusions: Higher weight gain in adulthood and larger amounts of ethanol intake were significantly associated with increased risk of $\mathrm{BC}$ in Japanese postmenopausal women. None of the investigated factors were significantly associated with BC risk in Japanese premenopausal women.
\end{abstract}

Keywords: Breast cancer - cohort study - menopausal status - weight gain - alcohol drinking

Asian Pac J Cancer Prev, 17 (3), 1437-1443

\section{Introduction}

Breast cancer $(\mathrm{BC})$ is the most common cancer among Japanese women. The incidence rate of BC is the highest among cancers in females, followed by colon cancer (Matsuda et al., 2013). The mortality rate of BC is also high, and 13,148 women died of BC in 2013. (Statistics and Information Department, Minister's Secretariat, Ministry of Health, Labour and Welfare, 2015). Accordingly, BC remains a great menace to Japanese women.

According to a review by Colditz et al. (2006), risk factors for BC were summarized as follows: younger age at menarche, smaller number of live births, older age at the first full-term pregnancy, older age at menopause, taller in body height, larger weight gain during adulthood, higher BMI, lower physical activity, smoking and drinking habits, family history of BC in first-degree relatives, and various dietary factors. Ovarian hormones, and estrogens, in particular, play an important role in etiology of BC (Henderson and Feigelson, 2000). Both endogenous and exogenous hormones increase cellular proliferation in the breast, thereby the likelihood of random genetic errors during cell proliferation (Henderson and Feigelson, 2000).

Hormonal milieus of postmenopausal women are different from premenopausal women in terms of amount of estrogen through reduction by menopause. For example, body fat has been suggested to be associated with increased risk of $\mathrm{BC}$ in postmenopausal women, 
but, in contrast, has been suggested to be associated with decreased risk of $\mathrm{BC}$ in premenopausal women (World Cancer Research Fund/ American Institute for Cancer Research, 2007). Hastert et al. (2013) examined six prevention recommendations such as body fatness, physical activity, energy density in foods, plant foods, red meat, and alcohol, for postmenopausal BC, according to the report by the World Cancer Research Fund and the American Institute for Cancer Research (2007). They concluded that adherence to recommendations, especially two recommendations for body fat and alcohol, could substantially reduce postmenopausal BC risk in U.S. women (Hastert et al. 2013).

In order to examine some of the above-mentioned recommendations in Japanese women, we conducted a cohort study on association of body height, weight gain since age 20, physical activity, and ethanol intake with BC risk according to menopausal status, using the latest data of the Japan Collaborative Cohort (JACC) study.

\section{Materials and Methods}

Details of the study subjects have been described elsewhere (Tamakoshi et al., 2013). Briefly, the baseline data of the JACC Study were collected from 1988 to 1990 , and 110,585 individuals (46,395 men and 64,190 women) aged 40 to 79 years in 45 study areas throughout Japan participated in the study. The follow-up survey for cancer mortality was conducted from the baseline, and finalized at the end of the 2009 year (Tamakoshi et al., 2013). In 24 of the 45 study areas, data on cancer incidence, such as date of diagnosis and primary site, were also collected simultaneously through population-based cancer registries or by reviewing the records of local major hospitals. We confined the analysis to these 24 areas available of cancer incidence information, excluding data of all the male subjects and women with previous diagnosis of BC.

Thus, data from the 38,610 (9,367 premenopausal, and 29,243 postmenopausal) women were used for analysis, and 273 (84 premenopausal, and 189 postmenopausal) cases of BC were newly diagnosed in 501,907 personyears. Because a part of the study areas discontinued the follow-up survey regarding cancer before 2009, the mean and median follow-up period of the incidence survey was 13.0 and 13.3 years, respectively, which were shorter than those of the mortality survey.

Among the variables in the baseline data, four explanatory variables, body height, weight gain since age 20, physical activity, and amount of ethanol intake per day, were selected for risk assessment for BC by menopausal status. Categorization of body height was referred to in two previous case-control studies of BC for Japanese women (Hirose et al., 2001; Kawai et al., 2013). Weight gain since age 20 was calculated as weight at baseline survey minus weight at age 20 , and categorized referring to an article by Suzuki et al. (2013).

Physical activity was categorized referring to an article by Suzuki et al. (2008). Namely, the most physically active women were defined as those whose time spent exercising per week was longer than or equal to one hour, and time spent walking per day was longer than or equal to one hour. Excluding the most physically active women, physically active women who exercised was defined as those whose time spent per week doing physical exercise was longer than or equal to one hour, and physically active women who walked was defined as those whose time spent walking per day was longer than or equal to one hour. Residual subjects were categorized as inactive women (Suzuki et al., 2008).

Amount of ethanol intake per day was defined as total amount per opportunity multiplied by frequency of consumption in a week, divided by seven, and then categorized referring to an article by Lin et al. (2005). If information of the subjects' menopausal status was missing in the administrated questionnaire, and if her age at baseline survey was 55 years or older, she was designated as a postmenopausal women.

The Cox proportional hazards regression model (the Cox model) was used to estimate hazards ratio (HR) and its $95 \%$ confidence interval (CI) of the explanatory variables for BC risk. For multivariable-adjusted analysis with the Cox model, age at the baseline survey (continuous variable), age at menarche (categorical variable), number of live births (categorical variable), and age at the first delivery (categorical variable), were involved in the model as potentially confounding factors. All statistical analyses were performed with EZR (Saitama Medical Center, Jichi Medical University, Saitama, Japan), which is a graphical user interface for $\mathrm{R}$ (The R Foundation for Statistical Computing, Vienna, Austria), and is a modified version of an $\mathrm{R}$ commander designed to add statistical functions frequently used in biostatistics (Kanda, 2013). Significance level was set up to a level of $5 \%$. This study was approved by the Ethics Boards at Hokkaido University Graduate School of Medicine, and Sapporo Medical University.

\section{Results}

Table 1 shows baseline characteristics of premenopausal and postmenopausal women in the JACC Study. Information of the four selected explanatory variables, body height, weight gain since age 20, physical activity, and amount of ethanol intake per day, and the four chosen potential confounding factors in the multivariable-adjusted analysis, age at baseline survey, age at menarche, number of live births, and age at the first delivery, were included in Table 1 by menopausal status.

Table 2 shows the results from the age-adjusted and the multivariable-adjusted analyses with the Cox model in premenopausal women. Amount of ethanol intake per day $\geq 15.0 \mathrm{~g}$ was significantly associated with increased risk of $\mathrm{BC}$ in the age-adjusted analysis $(\mathrm{HR}=2.38,95 \%$ CI 1.02-5.45), however, a significant association was not observed in the multivariable-adjusted analysis $(\mathrm{HR}=2.30$, 95\% CI 0.97-5.45). A significant trend of BC risk was not observed in amount of ethanol intake per day in neither the age-adjusted analysis ( $p$ for trend, $p=0.101$ ), nor in the multivariable-adjusted analysis ( $\mathrm{p}$ for trend, $\mathrm{p}=0.162$ ). Although the most physically active lifestyle was shown as about $40 \%$ reduction of $\mathrm{BC}$ risk in premenopausal women, it was not significant (multivariable-adjusted, 
Weight Gain and Alcohol Drinking as Breast Cancer Risk Factors in Japanese Postmenopausal Women - JACC Results

Table 1. Baseline Characteristics of Premenopausal and Postmenopausal Women in the JACC Study

\begin{tabular}{|c|c|c|}
\hline Variables & Premenopausal women & Postmenopausal women \\
\hline Number of individuals & 9,367 & 29,243 \\
\hline Age at baseline survey, mean (SD), in year & $45.5(3.8)$ & $62.4(7.8)$ \\
\hline Body height, mean(SD), in $\mathrm{cm}$ & $153.6(51.7)$ & $150.2(59.3)$ \\
\hline Body weight at age 20 , mean (SD), in $\mathrm{kg}$ & $49.7(59.3)$ & $49.7(65.3)$ \\
\hline Body weight, mean (SD), in kg & $53.8(72.7)$ & $51.6(78.9)$ \\
\hline Weight gain since age $20 \geq 10 \mathrm{~g}(\%)$ & 20.9 & 19.3 \\
\hline Most physically active $\$(\%)$ & 11.4 & 14.1 \\
\hline Amount of ethanol intake per day $\geq 15.0 \mathrm{~g}(\%)$ & 4.1 & 2.6 \\
\hline Age at menarche, mean (SD), in year & $14.0(1.5)$ & $15.3(1.8)$ \\
\hline Age at menopause mean (SD), in year & $\#$ & $48.7(4.7)$ \\
\hline Number of live births, mean (SD) & $2.3(0.9)$ & $2.8(1.4)$ \\
\hline Age at the first delivery, mean (SD), in year & $25.2(3.1)$ & $25.0(3.1)$ \\
\hline
\end{tabular}

SD: Standard deviation \#: Not applicable; \$: The most physically active lifestyle was defined as those for whom time spent on physical exercise per week was longer than or equal to one hour, and time spent walking per day was longer than or equal to one hour

Table 2. Hazard ratios (HRs) and their 95\% confidence intervals (CIs) of the four variables for premenopausal breast cancer risk by age-adjusted and multivariable-adjusted analysis with the Cox model.

\begin{tabular}{|c|c|c|c|c|c|c|c|c|c|c|c|}
\hline \multirow[b]{2}{*}{ Variables } & \multirow[b]{2}{*}{ Contents } & \multirow{2}{*}{$\begin{array}{c}\text { Number } \\
\text { of } \\
\text { subjects }\end{array}$} & \multirow{2}{*}{$\begin{array}{c}\text { Person- } \\
\text { years }\end{array}$} & \multirow{2}{*}{$\begin{array}{l}\text { Breast } \\
\text { cancer }\end{array}$} & \multirow{2}{*}{$\begin{array}{l}\text { Incidence } \\
\text { rate\# }\end{array}$} & \multicolumn{3}{|c|}{ Age-adjusted } & \multicolumn{3}{|c|}{ Multivariable-adjusted \& } \\
\hline & & & & & & HR & $95 \% \mathrm{CI}$ & $\begin{array}{c}\mathrm{P} \\
\text { value }\end{array}$ & HR\& & $95 \% \mathrm{CI}$ & $\begin{array}{c}\mathrm{P} \\
\text { value }\end{array}$ \\
\hline \multirow{5}{*}{ Body height } & $<149.0 \mathrm{~cm}$ & 1,394 & 20,098 & 13 & 6.5 & 1.00 & & & 1.00 & & \\
\hline & $\begin{array}{c}149.0- \\
152.9 \mathrm{~cm}\end{array}$ & 2,467 & 36,528 & 20 & 5.5 & 0.84 & $0.42-1.70$ & 0.633 & 0.94 & $0.37-2.36$ & 0.895 \\
\hline & $\begin{array}{c}153.0- \\
156.9 \mathrm{~cm}\end{array}$ & 2,783 & 41,111 & 25 & 6.1 & 0.93 & $0.48-1.83$ & 0.842 & 1.44 & $0.61-3.36$ & 0.405 \\
\hline & $\geq 157.0 \mathrm{~cm}$ & 2,535 & 38,172 & 26 & 6.8 & 1.03 & $0.53-2.03$ & 0.917 & 1.16 & $0.48-2.80$ & 0.748 \\
\hline & Total & 9,179 & 135,909 & 84 & 6.2 & & P for trend & 0.724 & & $\begin{array}{l}\mathrm{P} \text { for } \\
\text { trend }\end{array}$ & 0.476 \\
\hline \multirow{5}{*}{$\begin{array}{l}\text { Weight gain } \\
\text { since age } 20\end{array}$} & $<3.3 \mathrm{~kg}$ & 3,881 & 58,824 & 35 & 5.9 & 1.00 & & & 1.00 & & \\
\hline & $3.3-6.6 \mathrm{~kg}$ & 1,542 & 23,421 & 11 & 4.7 & 0.80 & $0.40-1.56$ & 0.506 & 0.89 & $0.42-1.89$ & 0.753 \\
\hline & $6.7-9.9 \mathrm{~kg}$ & 1,098 & 16,169 & 13 & 8.0 & 1.36 & $0.72-2.57$ & 0.348 & 1.27 & $0.59-2.70$ & 0.543 \\
\hline & $\geq 10.0 \mathrm{~kg}$ & 1,727 & 25,083 & 22 & 8.8 & 1.48 & $0.87-2.53$ & 0.149 & 1.46 & $0.78-2.73$ & 0.643 \\
\hline & Total & 8,248 & 123,497 & 81 & 6.6 & & $P$ for trend & 0.109 & & $\begin{array}{l}\mathrm{P} \text { for } \\
\text { trend }\end{array}$ & 0.221 \\
\hline \multirow{5}{*}{$\begin{array}{l}\text { Physical } \\
\text { activity }\end{array}$} & Inactive & 3,236 & 46,280 & 30 & 6.5 & 1.00 & & & 1.00 & & \\
\hline & $\begin{array}{l}\text { Active with } \\
\text { exercising }\end{array}$ & 840 & 12,014 & 12 & 10.0 & 1.54 & $0.79-3.01$ & 0.207 & 1.63 & $0.78-3.43$ & 0.197 \\
\hline & $\begin{array}{l}\text { Active with } \\
\text { walking }\end{array}$ & 2,991 & 45,085 & 26 & 5.8 & 0.90 & $0.53-1.52$ & 0.685 & 1.15 & $0.64-2.04$ & 0.643 \\
\hline & $\begin{array}{c}\text { Most } \\
\text { physically } \\
\text { active\$ }\end{array}$ & 913 & 13,679 & 5 & 3.7 & 0.57 & $0.22-1.46$ & 0.238 & 0.60 & $0.21-1.74$ & 0.348 \\
\hline & Total & 7,980 & 117,058 & 73 & 6.2 & & $P$ for trend & 0.282 & & $\begin{array}{l}\mathrm{P} \text { for } \\
\text { trend }\end{array}$ & 0.731 \\
\hline \multirow{5}{*}{$\begin{array}{l}\text { Amount } \\
\text { of ethano } \\
\text { intakel per } \\
\text { day }\end{array}$} & $0.0 \mathrm{~g}$ & 6,372 & 94,181 & 49 & 5.2 & 1.00 & & & 1.00 & & \\
\hline & $0.1-4.9 \mathrm{~g}$ & 723 & 10,418 & 10 & 9.6 & 1.81 & $0.92-3.58$ & 0.086 & 1.77 & $0.86-3.64$ & 0.122 \\
\hline & $5.0-14.9 \mathrm{~g}$ & 697 & 10,436 & 5 & 4.8 & 0.92 & $0.37-2.32$ & 0.866 & 0.84 & $0.30-2.34$ & 0.732 \\
\hline & $\geq 15.0 \mathrm{~g}$ & 334 & 4,877 & 6 & 12.3 & 2.38 & $1.02-5.45$ & 0.046 & 2.30 & $0.97-5.45$ & 0.060 \\
\hline & Total & 8,126 & 119,912 & 70 & 5.8 & & $P$ for trend & 0.101 & & $\begin{array}{l}\mathrm{P} \text { for } \\
\text { trend }\end{array}$ & 0.162 \\
\hline
\end{tabular}

\#: Incidence rate per 10,000 person-years; \$: See Table 1; \&: For the multivariable-adjusted analysis, four variables in Table 2 were involved in the model as categorical variables, in addition to age at the baseline survey (continuous variable), age at menarche (categorical variable), number of live births (categorical variable), and age at the first delivery (categorical variable) 
Table 3. Hazard Ratios (HRs) and their $95 \%$ Confidence intervals (CIs) of the four Variables for Postmenopausal Breast Cancer Risk by Age-adjusted and Multivariable-adjusted \& Analysis with the Cox Model

\begin{tabular}{|c|c|c|c|c|c|c|c|c|c|c|c|}
\hline \multirow{2}{*}{ Variables } & \multirow{2}{*}{ Contents } & \multirow{2}{*}{$\begin{array}{l}\text { Number } \\
\text { of } \\
\text { subjects }\end{array}$} & \multirow{2}{*}{$\begin{array}{l}\text { Person- } \\
\text { years }\end{array}$} & \multirow{2}{*}{$\begin{array}{l}\text { Breast } \\
\text { cancer }\end{array}$} & \multirow{2}{*}{$\begin{array}{c}\text { Incidence } \\
\text { rate\# }\end{array}$} & \multicolumn{3}{|c|}{ Age-adjusted } & \multicolumn{3}{|c|}{ Multivariable-adjusted } \\
\hline & & & & & & HR & $95 \% \mathrm{CI}$ & P value & HR & $95 \% \mathrm{CI}$ & $P$ value \\
\hline \multirow{5}{*}{ Body height } & $<149.0 \mathrm{~cm}$ & 10,139 & 126,994 & 56 & 4.4 & 1.00 & & & 1.00 & & \\
\hline & $\begin{array}{c}149.0- \\
152.9 \mathrm{~cm}\end{array}$ & 8,224 & 102,565 & 44 & 4.3 & 0.96 & $0.65-1.43$ & 0.847 & 1.13 & $0.67-1.91$ & 0.655 \\
\hline & $\begin{array}{c}153.0- \\
156.9 \mathrm{~cm}\end{array}$ & 5,652 & 70,765 & 49 & 6.9 & 1.54 & $1.04-2.28$ & 0.032 & 1.27 & $0.74-2.20$ & 0.385 \\
\hline & $\geq 157.0 \mathrm{~cm}$ & 3,411 & 41,719 & 31 & 7.4 & 1.64 & $1.04-2.58$ & 0.032 & 1.51 & $0.83-2.74$ & 0.181 \\
\hline & Total & 27,426 & 342,043 & 180 & 5.3 & & $\begin{array}{l}\mathrm{P} \text { for } \\
\text { trend }\end{array}$ & 0.007 & & $\begin{array}{l}\mathrm{P} \text { for } \\
\text { trend }\end{array}$ & 0.165 \\
\hline \multirow{5}{*}{$\begin{array}{l}\text { Weight gain } \\
\text { since age } 20\end{array}$} & $<3.3 \mathrm{~kg}$ & 12,113 & 153,494 & 52 & 3.4 & 1.00 & & & 1.00 & & \\
\hline & $3.3-6.6 \mathrm{~kg}$ & 3,244 & 42,156 & 22 & 5.2 & 1.53 & $0.93-2.53$ & 0.096 & 1.45 & $0.78-2.70$ & 0.246 \\
\hline & $6.7-9.9 \mathrm{~kg}$ & 2,333 & 29,560 & 27 & 9.1 & 2.67 & $1.67-4.26$ & $<0.001$ & 2.48 & $1.40-4.41$ & 0.002 \\
\hline & $\geq 10.0 \mathrm{~kg}$ & 4,220 & 52,912 & 52 & 9.8 & 2.88 & $1.96-4.24$ & $<0.001$ & 2.94 & $1.84-4.70$ & $<0.001$ \\
\hline & Total & 21,910 & 278,122 & 153 & 5.5 & & $\begin{array}{l}\mathrm{P} \text { for } \\
\text { trend }\end{array}$ & $<0.001$ & & $\begin{array}{l}\mathrm{P} \text { for } \\
\text { trend }\end{array}$ & $<0.001$ \\
\hline \multirow{5}{*}{$\begin{array}{l}\text { Physical } \\
\text { activity }\end{array}$} & Inactive & 8,700 & 99,519 & 68 & 6.8 & 1.00 & & & 1.00 & & \\
\hline & $\begin{array}{c}\text { Active } \\
\text { with } \\
\text { exercising }\end{array}$ & 2,597 & 30,443 & 22 & 7.2 & 1.08 & $0.67-1.75$ & 0.745 & 1.15 & $0.65-2.04$ & 0.635 \\
\hline & $\begin{array}{c}\text { Active } \\
\text { with } \\
\text { walking }\end{array}$ & 7,867 & 100,728 & 44 & 4.4 & 0.64 & $0.43-0.94$ & 0.021 & 0.79 & $0.50-1.23$ & 0.291 \\
\hline & $\begin{array}{c}\text { Most } \\
\text { physically } \\
\text { active } \$\end{array}$ & 3,154 & 39,337 & 13 & 3.3 & 0.50 & $0.28-0.91$ & 0.024 & 0.53 & $0.26-1.10$ & 0.087 \\
\hline & Total & 22,318 & 270,027 & 147 & 5.4 & & $\begin{array}{l}P \text { for } \\
\text { trend }\end{array}$ & 0.003 & & $\begin{array}{l}P \text { for } \\
\text { trend }\end{array}$ & 0.067 \\
\hline \multirow{5}{*}{$\begin{array}{l}\text { Amount } \\
\text { of ethanol } \\
\text { intake per } \\
\text { day }\end{array}$} & $0.0 \mathrm{~g}$ & 21,123 & 270,090 & 131 & 4.9 & 1.00 & & & 1.00 & & \\
\hline & $0.1-4.9 \mathrm{~g}$ & 1,650 & 19,616 & 13 & 6.6 & 1.35 & $0.76-2.39$ & 0.309 & 1.25 & $0.64-2.41$ & 0.515 \\
\hline & $5.0-14.9 \mathrm{~g}$ & 1,411 & 15,890 & 7 & 4.4 & 0.89 & $0.42-1.91$ & 0.771 & 0.49 & $0.15-1.56$ & 0.227 \\
\hline & $\geq 15.0 \mathrm{~g}$ & 633 & 6,697 & 9 & 13.4 & 2.72 & $1.38-5.36$ & 0.004 & 2.74 & $1.32-5.70$ & 0.007 \\
\hline & Total & 24,817 & 312,293 & 160 & 5.1 & & $\begin{array}{l}\mathrm{P} \text { for } \\
\text { trend }\end{array}$ & 0.041 & & $\begin{array}{l}\text { P for } \\
\text { trend }\end{array}$ & 0.174 \\
\hline
\end{tabular}

\#: Incidence rate per 10,000 person-years; \$: See Table 1; \&: For the multivariable-adjusted analysis, four variables in Table 3 were involved in the model as categorical variables, in addition to age at the baseline survey (continuous variable), age at menarche (categorical variable), number of live births (categorical variable), and age at the first delivery (categorical variable)

$\mathrm{HR}=0.60,95 \% \mathrm{CI} 0.21-1.74)$. None of the other variables were associated with risk of $\mathrm{BC}$ in premenopausal women, either.

Table 3 shows the results from the age-adjusted and the multivariable-adjusted analyses with the Cox model in postmenopausal women. Body height of $153.0 \mathrm{~cm}$ $156.9 \mathrm{~cm}$, and $\geq 157.0 \mathrm{~cm}$ was significantly associated with increased risk of $\mathrm{BC}$ in the age-adjusted analysis $(\mathrm{HR}=1.54,95 \%$ CI $1.04-2.28$, and $\mathrm{HR}=1.64,95 \%$ CI 1.04-2.58, respectively), and significantly increased trend of $\mathrm{BC}$ risk was also observed in body height in the age-adjusted analysis ( $p$ for trend, $\mathrm{p}=0.007$ ). However, the multivariable-adjusted analysis revealed that body height was not significantly associated with risk of BC ( $\mathrm{p}$ for trend, $\mathrm{p}=0.165$ ).

Weight gain since age 20 of $6.7 \mathrm{~kg}-9.9 \mathrm{~kg}$, and $\geq 10.0$ $\mathrm{kg}$ were significantly associated with increased risk of BC, even in the multivariable-adjusted analysis $(\mathrm{HR}=2.48$,
95\% CI 1.40-4.41, and HR=2.94, 95\% CI 1.84-4.70, respectively). Significantly increased trend of BC risk was also observed in weight gain since age 20, even in the multivariable-adjusted analysis ( $\mathrm{p}$ for trend, $\mathrm{p}<0.001$ ).

Being physically active by walking and being the most physically active was significantly associated with reduced risk of $\mathrm{BC}$ in the age-adjusted analysis $(\mathrm{HR}=0.64$, 95\% CI 0.43-0.94, and $\mathrm{HR}=0.50,95 \%$ CI $0.28-0.91$, respectively), and significantly decreased trend of $\mathrm{BC}$ risk was also observed in physical activity level in the age-adjusted analysis ( $\mathrm{p}$ for trend, $\mathrm{p}=0.003$ ). However, the multivariable-adjusted analysis showed that being the most physically active was not significantly associated with reduced risk of $\mathrm{BC}(\mathrm{HR}=0.53,95 \%$ CI 0.26-1.10), and a significant trend was not observed in the physical activity level $(\mathrm{p}=0.067)$.

Amount of ethanol intake per day $\geq 15.0 \mathrm{~g}$ was significantly associated with increased risk of $\mathrm{BC}$, even in the multivariable-adjusted analysis $(\mathrm{HR}=2.74,95 \% \mathrm{CI}$ 
Weight Gain and Alcohol Drinking as Breast Cancer Risk Factors in Japanese Postmenopausal Women - JACC Results

1.32-5.70), although an increased trend of BC risk was not observed in amount of ethanol intake per day in the multivariable-adjusted analysis ( $\mathrm{p}$ for trend, $\mathrm{p}=0.174$ ).

\section{Discussion}

We investigated the four risk factors of $\mathrm{BC}$ by menopausal status, using the latest data from the JACC Study. Firstly, body height had never been assessed with regard to risk of BC in the JACC Study, and we found that taller body height was not associated with increased risk of BC if multivariable adjustment was performed. Secondly, consistent with the previous report from the JACC Study (Suzuki et al., 2013), higher weight gain since age 20 was significantly associated with increased risk of BC only in postmenopausal women. Thirdly, inconsistent with the previous report from JACC Study (Suzuki et al., 2008), level of physical activity was not associated with risk of $\mathrm{BC}$, although some risk reduction was noted in a higher level of physical activity. Fourthly, ethanol intake had never been shown as being related to BC risk by menopausal status in the JACC Study, and we found that ethanol intake per day $\geq 15 \mathrm{~g}$ was associated with increased risk of BC in postmenopausal women. It is thought that similar results for Japanese women were noted compared with those for U.S. women reported by Hastert et al. (2013), because they showed that adherence to two recommendations for body fat and alcohol intake was significantly associated with decreased risk for postmenopausal BC.

As stated by Vrieling et al (2010), weight gain is thought to be a better measure to assess adiposity and its metabolic consequences than BMI, and this is the reason why we chose it for analysis. According to a review (World Cancer Research Fund/ American Institute for Cancer Research, 2007), there is a substantial amount of epidemiological evidence showing an inverse relationship between greater body fat and risk of premenopausal BC, especially, among women in western countries. However, Emaus et al. (2014) recently reported from a pooled analysis of European cohort studies that a positive relationship between weight gain in adulthood and risk of $\mathrm{BC}$ was observed in women before or at age 50. Furthermore, pooled analysis in Japanese cohort studies (Wada et al., 2014) revealed that higher BMI was significantly associated with increased risk of $\mathrm{BC}$, not only in postmenopausal women, but also, in premenopausal women. Our findings on positive, but, insignificant association of weight gain since age 20 with risk of premenopausal $\mathrm{BC}$ have indicated that body fat is not inversely associated with BC risk in Japanese premenopausal women.

According to a meta-analysis by Vrieling et al. (2010), the association between adult weight gain and postmenopausal BC risk was stronger for estrogenreceptor positive $\mathrm{BC}$ than the other type. Their findings suggested that higher weight gain in adulthood may increase risk of $\mathrm{BC}$ via elevated estrogen exposure. Another possible mechanism is, as indicated from the results of the prospective study conducted by Muti et al. (2002), increased levels of insulin-like growth factor (IGF)-I which is observed in high weight-gain women.
High alcohol consumption has been reported to increase risk of BC in premenopausal (Petri et al., 2004; Suzuki et al., 2009) and postmenopausal women (Petri et al., 2004; Tjonneland et al., 2004; Suzuki et al., 2009). Suzuki et al. (2009) reported from the results of another cohort study in Japan called the JPHC Study that the relationship between alcohol consumption and risk of BC was found not only in premenopausal women, but also in postmenopausal women. Petri et al. (2004) reported that a large intake of alcohol was associated with increased risk both in premenopausal women and postmenopausal women older than 70 years. Tjonneland et al. (2004) showed that alcohol intake in the fifties increased risk of postmenopausal BC.

Although a U-shaped relationship of ethanol intake with $\mathrm{BC}$ risk was observed in postmenopausal women of our study, there are few reports which have suggested the U-shaped relationship, to our knowledge. Therefore, more evidence would be necessary to substantiate the U-shaped relationship, if any. According to a review of the mechanism of alcohol mediated mammary carcinogenesis by Seitz et al. (2012) alcohol increased estrogen levels, and estrogen may exert its carcinogenetic effect on breast tissue either via the estrogen receptor or directly. Other mechanisms may include acetaldehyde, oxidative stress, and epigenetic changes caused by alcohol consumption (Seitz et al., 2012).

Several cohort studies indicated that taller body height was associated with increased risk of BC in premenopausal (Kabat et al., 2013) and postmenopausal (Iwasaki et al., 2007; Fagherazzi et al., 2012; Kabat et al., 2013; Stenndof et al., 2013) women, even if potential confounding factors were adjusted. Unlike these studies, we found that taller body height was not associated with risk of $\mathrm{BC}$ in the multivariable-adjusted analysis. There are at least two case-control studies of body height for BC risk in Japanese women (Hirose et al., 2001; Kawai et al., 2013), and one study showed a significant positive association only in postmenopausal women (Hirose et al., 2001), but, another study did not show the association either in premenopausal or in postmenopausal women (Kawai et al., 2013). Further study is necessary to clarify the association between body height and BC risk in Japanese women.

A higher level of physical activity has been reported to reduce risk of $\mathrm{BC}$ in premenopausal (Maruti et al., 2008) and postmenopausal women (Maruti et al., 2008; Peters et al., 2009) even if potential confounding factors were adjusted. The mechanism of the inverse relationship between physical activity level and $\mathrm{BC}$ risk has been explained by lower endogenous estradiol concentration in women with higher regular physical activity levels (Chan et al., 2007). However, our study did not suggest a significant inverse association of higher physical activity with BC risk. Since level of physical activity was defined using only two items in the questionnaire in our study, a more precise definition might have induced a validating result of the association between physical activity and $\mathrm{BC}$ risk.

Some limitations in this study should be considered for interpreting our results. First, because we collected information about menopausal status at the baseline survey, 
but, not at $\mathrm{BC}$ onset, the possibility of misclassification of menopausal status at BC onset should be considered. Second, our data analyses relied on self-reported information at baseline, and that information was not updated during follow-up. However, Zhu et al. (2002) reported high short-term and long-term reliability for 440 participants who were selected from the JACC Study. Third, the cohort population of the JACC Study was not established by random sampling. However, it was shown that they were similar to the Japanese general population in light of several demographic and lifestyle features (Ohno et al., 2001).

In conclusion, higher weight gain in adulthood, and higher ethanol intake were significantly associated with increased risk of BC in Japanese postmenopausal women. None of the investigated factors were significantly associated with BC risk in Japanese premenopausal women. Further study is required to provide valid recommendations for preventing BC in Japanese premenopausal and postmenopausal women.

Members of the JACC Study Group: The present members of the JACC Study Group who co-authored this paper are: Dr. Akiko Tamakoshi (present chairperson of the study group), Hokkaido University Graduate School of Medicine, Dr. Mitsuru Mori, Sapporo Medical University School of Medicine, Dr. Yoshihiro Kaneko, Akita University Graduate School of Medicine, Dr. Ichiro Tsuji, Tohoku University Graduate School of Medicine, Dr. Yosikazu Nakamura, Jichi Medical School, Dr. Hiroyasu Iso, Osaka University School of Medicine, Dr, Kazumasa Yamagishi, Faculty of Medicine, University of Tsukuba, Dr. Haruo Mikami, Chiba Cancer Center, Dr. Michiko Kurosawa, Juntendo University School of Medicine

Dr. Yoshiharu Hoshiyama, Yokohama Soei University, Dr. Naohito Tanabe, University of Niigata Prefecture, Dr. Koji Tamakoshi, Nagoya University Graduate School of Health Science, Dr. Kenji Wakai, Nagoya University Graduate School of Medicine, Dr. Shinkan Tokudome, National Institute of Health and Nutrition, Dr. Koji Suzuki, Fujita Health University School of Health Sciences, Drs. Shuji Hashimoto and Hiroshi Yatsuya, Fujita Health University School of Medicine, Dr. Shogo Kikuchi, Aichi Medical University School of Medicine, Dr. Yasuhiko Wada, Faculty of Nutrition, University of Kochi, Dr. Takashi Kawamura, Kyoto University Health Service, Dr. Yoshiyuki Watanabe, Kyoto Prefectural University of Medicine Graduate School of Medical Science, Dr. Kotaro Ozasa, Radiation Effects Research Foundation, Dr. Kazuya Mikami, Kyoto Prefectural University of Medicine Graduate School of Medical Science, Dr. Chigusa Date, School of Human Science and Environment, University of Hyogo, Dr. Kiyomi Sakata, Iwate Medical University, Dr. Yoichi Kurozawa, Tottori University Faculty of Medicine, Drs. Takesumi Yoshimura and Yoshihisa Fujino, University of Occupational and Environmental Health, Dr. Akira Shibata, Kurume University, Dr. Naoyuki Okamoto, Kanagawa Cancer Center, and Dr. Hideo Shio, Long-Term Care Health Facility Caretown Minamikusatsu, Shiga.

\section{Acknowledgements}

We wish to express our sincere thanks to Drs. Kunio Aoki and Yoshiyuki Ohno, Professors Emeritus of the Nagoya University School of Medicine and former chairpersons of the JACC Study. We are also greatly indebted to Dr. Haruo Sugano, former Director of the Cancer Institute, Tokyo, who contributed greatly to the initiation of the JACC Study, to Dr. Tomoyuki Kitagawa, Director Emeritus of the Cancer Institute of the Japanese Foundation for Cancer Research and former project leader of the Grant-in-Aid for Scientific Research on Priority Area 'Cancer', and to Dr. Kazao Tajima, Aichi Cancer Center and previous project leader of the Grantin Aid for Scientific Research on Priority Area of Cancer Epidemiology, for their encouragement and support during this study.

\section{References}

Chan M-F, Dowsett M, Folkerd E, et al (2007) Usual physical activity and endogenous sex hormones in postmenopausal women: the European prospective investigation into cancernorfolk population study. Cancer Epidemiol Biomarkers Prev, 16, 900-5.

Colditz GA, Baer HJ, Tamimi RA (2006) 51. Breast Cancer. schottenfeld d, fraumeni jf eds. cancer epidemiology and prevention. third ed. oxford univ press, oxford, 995-1012.

Emaus MJ, van Gills CH, Bakker MF, et al (2014). Weight change in middle adulthood and breast cancer risk in the EPIC-PANACEA study. Int J Cancer, 135, 2887-99.

Fagherazzi G, Viller A, Boutron-Ruault MC, et al (2012). Height, sitting height, and leg length in relation with breast cancer risk in the E3N Cohort. Cancer Epidemiol Biomarkers Prev, 21, 1171-5.

Hastert TA, Beresford SAA, Patterson RE, et al (2013). Adherence to WCRF/AICR cancer prevention recommendation and risk of postmenopausal breast cancer. Cancer Epidemiol Biomarkers Prev, 22, 1498-1508.

Henderson BE, Feigelson HS (2000). Hormonal carcinogenesis. Carcinogenesis, 21, 427-33.

Hirose K, Tajima K, Hamajima N, et al (2001). Association of family history and other risk factors with breast cancer risk among Japanese premenopausal and postmenopausal women. Cancer Causes Control, 12, 349-58.

Iwasaki M, Otani T, Inoue M, et al (2007). Body size and risk for breast cancer in relation to estrogen and progesterone receptor status in Japan. Ann Epidemiol, 17, 304-12.

Kabat GC, Heo M, Kamensky V, et al (2013). Adult height in relation to risk of cancer in a cohort of Canadian women. Int J Cancer, 132, 1125-32.

Kanda Y (2013). Investigation of the freely-available easy-touse software "EZR" (Easy R) for medical statistics. Bone Marrow Transplant, 48, 452-8.

Kawai M, Kakugawa Y, Nishino Y, et al (2013). Anthropometric factors, physical activity, and breast cancer risk in relation to hormone receptor and menopausal status in Japanese women: a case-control study. Cancer Causes Control, 24, 1033-44.

Lin Y, Kikuchi S, Tamakoshi K, et al (2005). Prospective study of alcohol consumption and breast cancer risk in Japanese women. Int J Cancer, 116, 779-83.

Matsuda A, Matsuda T, Shibata A, et al (2013). Cancer incidence and incidence rates in Japan in 2008: A Study of 25 population-based cancer registries for the Monitoring of Cancer Incidence in Japan (MCIJ) Project. Jpn J Clin Oncol, 44, 388-96. 
Maruti SS, Willett WC, Feskanich D, et al (2008). A prospective study of age-specific physical activity and premenopausal breast cancer. J Natl Cancer Inst, 100, 728-37.

Muti P, Quattrin T, Grant BJB, et al (2002). Fasting glucose is a risk factor for breast cancer: a prospective study. Cancer Epidemiol Biomarkers Prev, 11, 1361-8.

Ohno Y, Tamakoshi A (2001). Japan collaborative cohort study for evaluation of cancer risk sponsored by monbusho (JACC Study). J Epidemiol, 11, 144-50.

Peters TM, Schatzkin A, Gierach GL, et al (2009). Physical activity and postmenopausal breast cancer risk in the NIHAARP Diet and Health Study. Cancer Epidemiol Biomarkers Prev, 18, 289-96.

Petri AL, Tjonneland A, Gamborg M, et al (2004). Alcohol intake, type of beverage, and risk of breast cancer in pre- and postmenopausal women. Alcohol Clin Exp Res, 28, 1084-90.

Seitz HK, Pelucchi C, Bagnardi V, et al (2012) Epidemiology and pathophysiology of alcohol and breast cancer: update 2012. Alcohol Alcohol, 47, 204-12.

Stenndof K, Ritte R, Eomios PP, et al (2013). Physical activity and risk of breast cancer overall and by hormone receptor status: the European Prospective Investigation into Cancer and Nutrition. Int J Cancer, 132, 1667-78.

Suzuki R, Iwasaki M, Inoue M, et al (2009). Alcohol consumption-associated breast cancer incidence and potential effect modifiers: the Japan public health centerbased Prospective Study. Int J Cancer, 127, 685-95.

Suzuki S, Kojima M, Tokudome S, et al (2008). Effect of physical activity on breast cancer risk: findings of the japan collaborative cohort study. Cancer Epidemiol Biomarkers Prev, 17, 3396-401.

Suzuki S, Kojima M, Tokudome S, et al (2013). Obesity/ weight gain and breast cancer risk: findings from the japan collaborative cohort study for the evaluation of cancer risk. $J$ Epidemiol, 23, 139-45.

Tamakoshi A, Ozasa K, Fujino Y, et al (2013). Cohort profile of the japan collaborative cohort study at final follow-up. $J$ Epidemiol, 23, 227-32.

Tjonneland A, Christensen J, Thomsen BL, et al (2004). Lifetime alcohol consumption and postmenopausal breast cancer rate in Denmark: a prospective cohort study. J Nutr, 134, 173-8.

Statistics and Information Department, Minister's Secretariat, Ministry of Health, Labour and Welfare (2015). Vital Statistics of Japan 2013. Vol 3. Tokyo: Health Labour and Welfare Statistics Association, Tokyo, 146-7.

Vrieling A, Buck K, Kaaks R, et al (2010). Adult weight gain in relation to breast cancer risk by estrogen and progesterone receptor status. Breast Cancer Res Treat, 123, 641-9.

Wada K, Nagata C, Tamakoshi A, et al (2014). Body mass index and breast cancer risk in Japan: a pooled analysis of eight population-based cohort studies. Ann Oncol, 25, 519-24.

World Cancer Research Fund/ American Institute for Cancer Research (2007). Food, nutrition, physical activity, and the prevention of cancer: a global perspective. washington DC, 289-95.

Zhu S, Toyoshima H, Kondo T, et al (2002). Short-term and long-term reliability on previous illness and family history as compared with that on smoking and drinking habits in questionnaire survey. J Epidemiol, 12, 120-5. 